designed for such use, and in order that it may not be confused in appearance with the standard mixture ${ }^{1}$ it is being marketed with a trace of pink colour added to it ${ }^{2}$.

The following points should be noted with regard to its use.

(1) For successful ribboning, ester wax should be cut much more slowly than paraffin wax. It is essential that the block sides should be straight and parallel, and that a stout, sharp knife should be used.

(2) The block should be warmed before trimming, otherwise the wax shatters and flies over the bench.

(3) After standing some weeks in the molten condition in an oven, a slight separation of the constituents may be seen. A little heating over a bunsen burner will make these pass into solution again.

(4) A clearer block is made if the wax is heated a few degrees above its melting point before being poured into the $L$ moulds. The infiltrated specimen should be introduced into the mould when a thin skin of wax is seen next to the $L$ pieces. Cool in water; but do not submerge.

(5) Tropical ester wax is soluble in alcohols, ethers, esters, ketones, hydrocarbons, etc. Ethylene glycol, mono ethyl ether or cedarwood oil are recommended as clearing agents.

${ }^{1}$ Steedman, H. F., Quart. J. Micro. Soc., 88, Third Series, No. 1. ${ }^{2}$ The British Drug Houses, Poole, Dorset.

$|0| 2$

\section{SETTLING BEHAVIOUR OF THE OYSTER LARVA}

$\mathrm{T}$ HE larval habits and settling behaviour of the European flet oyster (Ostrea edulis) have been extensive(f whatied at the Fisheries Experiment Statio A Conway, witom of recent years the work of Dif A. A. Cols and his collaborators has given greatly improv@ tohniques for breeding and rearing on a copmer al scale. The task of reviving the depleted oyspr fisheries in Great Britain is proving decidedly more difficult than that of similar fisheries on the other side of the Atlantic, where the American oyster (Gryphoea virginica) has proved more amenable to cultivation. The work at Conway now takes a further step forward with the publication by Dr. Cole and Mr. E. W. Knight Jones of the results of their investigations from 1939 onwards*.

In this noteworthy contribution to oyster biology two points of major significance emerge. The first is one the implication of which has a bearing on general problems of marine larval settlement, particularly those of gregarious species. The experiments showed that oyster larvæ tended to settle more readily on shells which already bore recently attached spat than on similar shells devoid of spat, especially so when the spat fall was not very intense. The authors suggest that settlement is encouraged by a substance secreted into the surrounding water by the spat and perhaps also by fully developed larvæ. If further experiments should prove that this suggestion is indeed fact, a significant advance will have been made.

The second discovery is of even more immediate importance to the oyster cultivator. It has long been thought that cultch intended to catch a spat fall

* The Setting Behaviour of Larvæ of the European Flat Oyster (Ostrea edulis I.) and its Influence on Methods of Cultivation and Spat Collection. Fishery Investigations, Series 2, 17, No. 3. Pp. 39. (London: H.M. Stationery Office, 1949.) 28. net. should be perfectly clean and therefore should not be immersed until just before the larvæ are expected to settle. The results of experiments in comparing clean shells with shells already fouled by the settle. ment of other organisms completely contradicted this long-standing belief. In the experiments, larvæ settled abundantly on shells fouled with other sedentary organisms and in much less concentration on clean shells. Freedom from silt is, however essential, and the practical problem for the cultivator resolves itself into how to produce a sufficient degree of fouling of his cultch to make it attractive without it becoming smothered in silt. It is evident that local conditions will greatly influence procedure, and that bouquets of tiles should remain largely free from falling silt in localities where shells scattered loosely over the bottom will quickly be covered.

This is a paper which no oyster cultivator can afford to ignore, and which no marine biologist interested in general problems of larval settlement and ecological distribution will forget.

\section{THE MAYA CIVILIZATION OF YUCATAN}

A $\mathrm{T}$ a meeting of the Royal Society of Edinburgh $A$ on October 24, an address on "The Maya Civilization of Yucatan" was given by Dr. Douglas Guthrie, of the Department of the History of Modicine, University of Edinburgh. He said that the Maya people have been called the 'Greeks of the West', a comparison which is fully justified. The study of the aboriginal inhabitants of America is only just beginning. Many cities still lie buried in the jungle, but the wonders of the sites already excavated, such as those at Chichen Itzá and Uxmal, reveal only a partial picture of the Mayan glory of the past. The civilizations of the Inca of Peru and of the Aztec of Mexico lacked the splendour of the Maya of Central America.

During the eighteenth and nineteenth centuries there was much argument regarding the origin of the races and cultures of America, resulting in a confused condition of American archæology which has continued to the present time. Inca and Aztec cultures were still in progress at the date of the Spanish Conquest, but that of the Maya, the greatest of the three, dating from A.D. 300 or earlier, had come to an end before the Spaniards landed. About 1843, publication of Prescott's account of the Conquest, and of the travels of Stephens and Catherwood, revealed to the world the existence, in the western hemisphere, of buildings comparable to those of Egypt and Greece.

Since then, each fresh discovery has added to the tale of Maya greatness. Their two most noteworthy accomplishments were the cultivation of maize and, probably deriving from this, the invention of a calendar. To this day maize, in the form of 'tortillas', remains the staple food of the so-called Indians. The remarkable ruins at Chichen Itzá include the pyramids, the ball-court, and various temples, many of them adorned with stone carvings of snakes, the feathered snake or plumed serpent being a favourite theme. The modern Maya, about a quarter of a million in number, are happy people, with a love of music and $a$ sense of humour, although little remains of the ancient culture. 